・物种概念专题・

\title{
居群、物种与生物多样性
}

\author{
陈家宽* \\ (复旦大学生物多样性科学研究所, 上海 200433)
}

\section{Population, species and biodiversity}

\author{
Jiakuan Chen ${ }^{*}$
}

Institute of Biodiversity Science, Fudan University, Shanghai 200433

受《生物多样性》主编之邀, 我对洪德元先生 (2016)的“生物多样性事业需要科学、可操作的物种 概念”一文谈一点体会。鉴于在学术声望上我只能 望洪先生之项背以及“可操作性的物种概念”之复杂 性, 我后悔轻率答应了撰文。但为了引起我国植物 分类与系统植物学界关注这一重要问题的讨论, 我 不得不勉为其难。

\section{1 三个目的}

我理解，洪先生撰写此文有三个非常明确的 目的:

第一, 他以熟知的药药属 (Paeonia) 植物为例, 指出科学认识物种是有效保护我国珍稀濒危物种 的基石。1992年出版的《中国植物红皮书》(傅立国 和金鉴明, 1992)将黄牡丹(Paeonia delavayi Franch. var. lutea (Franch.) Finet et Gagnep)收录为354个保 护单元之一。但洪先生根据他的课题组长期野外生 物学研究和依据 26 个单拷贝或臭拷贝核基因DNA 序列对牡丹组作了系统发生分析后, 可以确定西藏 东南部的“黄牡丹”与其他广大地区的“黄牡丹”有 别。它们分明是两个独立的物种, 即大花黄牡丹 $(P$. ludlowii)和滇牡丹 (P. delavayi)。滇牡丹广泛分布, 并 不是濒危物种, 而大花黄牡丹局域分布, 仅有 5 个 居群, 是真正的濒危物种, 但被红皮书掩埋在并不 濒危的“黄牡丹”中, 其有限的居群却正在遭受近乎 毁灭性的破坏。

中国是世界上生物多样性最丰富的少数几个 国家之一, 我们只有正确认识保护对象如独特的生

收稿日期: 2016-08-15; 接受日期: 2016-09-07

* 通讯作者 Author for correspondence. E-mail: jkchen@fudan.edu.cn
态系统、珍稀濒危物种和重要遗传资源, 保护才能 达到预期效果。据报道，至2014年底我国已建立自 然保护区 2,729 个, 总面积 147 万平方公里, 约占陆 地国土面积的 $14.84 \%$ (www.zhb.gov.cn), 高于全球 $12.7 \%$ 的水平; 主要生态系统类型、自然遗迹和 $85 \%$ 以上的国家重点保护野生动植物在自然保护区内 得到了保护。坦言之, 我在担任国家级自然保护区 评审委员会副主任的 10 年时间中, 从所看到的数以 百计的《科学考察集》质量来评判, 黄牡丹这样的 例子并不少见, 已确定的国家重点保护野生动植物 物种中有相当一部分还缺少充分的科学认识。

第二, 他从《中国植物志》受到国内外学术界 的批评着眼, 指出合理划分物种是提高《中国植物 志》质量的重要保障。《中国植物志》是目前世界 上记载植物种类最丰富的一部巨著, 全书 80 卷 126 册，记载了中国301科3,408属31,142种，包括植物 的学名、形态、生境、分布、用途和物候等。该志 书基于中国数以百位计的植物学家 80 年的研究积 累, 历经 45 年艰辛编撰才得以于 2004 年全部完成, 是我国现代科学发展史中的重要标志性成就之一。 但鉴于绝大多数作者是经典植物分类学家, 采用的 是形态-地理的物种概念和模式标本的方法, 再加 上历史局限, 缺少编撰世界专科专属的经验和现代 生物学研究背景, 因此, 以新的物种概念修订出版 新一代《中国植物志》势在必行。

第三，他提出科学、可操作的“形态-生物学物 种概念”, 引导中国分类与系统植物学家在核心概 念上进入国际学术舞台。从1753年林奈的《植物种 
志》(Species Plantarum)到达尔文的《物种起源》, 特 别是后者问世以来, 物种概念、物种形成过程与机 制和系统发育关系等几乎一直是现代生物学中不 断争议的少数几个核心话题之一。欧美和日本等发 达国家和地区在这一核心话题上处于主导地位，而 我国生物学家在国际学术界几乎没有发声, 在国内 学术刊物上也极少看到有见地的相关论文。洪先生 一反他多年用英语写作并在国际刊物上发表论文 的常态, 提出新的物种概念发表在 《生物多样性》 上, 以期引起大家对 “形态-生物学物种概念”进行 讨论, 引导中国分类与系统植物学家参与现代生物 学核心概念的思考。

\section{2 三个贡献}

我以为, 洪先生此文有三个学术上的贡献:

第一, 指出了物种问题在学术上与在生物多样 性保护事业中的重要地位, 以期引起中国学术界对 物种问题的关注。

第二, 对4位学者即Mayden (2002, 梳理与评论 了多达 24 个物种概念)、Wilkins (2009, 梳理与评论 了多达 26 个物种概念) 以及周长发和杨光(2011, 梳 理与评论了多达 68 个物种概念)提到的较为流行的 物种概念重新归成以下 6 类: (1)强调生殖隔离的物 种概念 (5个); (2)强调基因差异的物种概念(3个); (3) 强调进化的物种概念 (3个); (4)强调系统发生或支序 分类理论的物种概念 (7个); (5)强调生态的物种概念 (1个); (6) 强调外部形态的物种概念 (4个)。我认为, 相比之下, 洪先生的重新归类更合乎逻辑, 也更便 于理解。特别精彩的是洪先生在6类中选择最有代 表性的各个物种概念对其内涵、演变、异同和不足 进行了评述。这无疑为读者提供了打开进入该领域 大门的一把钥匙, 也是了解其学术思想的捷径。

第三，提出“形态-生物学物种概念”。这一新概 念基于形态, 但吸收了生物学物种、遗传学物种、 进化物种以及系统发生物种等概念的优点, 摒弃它 们的不足和问题。他还以药药属几个类群中的物种 处理为例, 说明这一新的物种概念是可操作的, 并 得到基于分子证据的系统发生分析的强有力支持。 这是我国学者首次提出的物种概念。

\section{3 三个启示}

我在拜读“生物多样性事业需要科学、可操作
的物种概念”一文后有以下三点启示可供读者 讨论:

第一, 分类学的物种与生物学的物种。分类是 人类区分客观世界从而掌握客观世界规律的基本 方法。生物分类学的目的是建立一个全球生物的信 息归档与查询系统，包括生物的界、门、纲、目、 科、属、种(亚种、变种、变型)等级系统。有了这 一信息归档与查询系统, 生物学家可将研究某一类 群(如物种)后所获得的信息归档于这一系统下, 其 他生物学家只要知道类群(通常是物种)的名称就能 从这一系统中查询到该类群的大量信息。作为面向 公众的信息归档与查询系统, 就要求系统有一定稳 定性、可操作性和可预期性。因此, 分类学的物种 主要是采用形态-地理的标准, 有以上非常明确的 功利性目的。

生物学的物种是为了追求物种的真实性, 并 试图提出一套大家公认又有操作性的划分物种的 客观标准。事实上, 尽管这些研究者往往从形态、 繁殖、遗传、生态、进化等不同角度或者多学科研 究物种, 让大家对物种真实性的认识有了革命性 的变化, 但没有人能颠覆分类学的物种概念与方 法。原因无非有两个: (1)全球生物多样性中的物种 形成过程、机制和模式远远比我们想象的复杂; (2) 分类学的物种概念与划分方法有其客观性与可操 作性。

以我的理解, 洪先生提出“科学、可操作的物种 概念” 的目的是想把两者统一起来, 这是中国学者 的大胆尝试, 但毕竟所有案例都来源于药药属, 我期望这一概念得到其他类群研究结果的强烈 支持。

第二, 居群(population)概念与模式(type)概念。 英国著名植物分类学家Heywood在1967年明确指 出, 我们面对的每一个物种都是一个居群系统 (Heywood, 1979)。自然物种并不是由个体直接组成, 而是个体在特定时空中按照一定规律集合而成居 群，再由不同的居群有规律地组成物种。毫无疑问， 研究物种的居群系统比研究一份一份标本更能获 得对一个物种的科学认识。而经典分类学家采用的 是模式概念与模式标本的方法, 这种方法强调在命 名一个新物种时, 必须要指定模式标本(个体), 也 只有与模式标本比较后有“足够”差异时才能命名一 个新类群。换句话说, 这一模式标本“代表”了该物 


\section{生态多样性 Ecological diversity}

生物群区 Biomes

生物区 Bioregions

景观 Landscapes

生态系统 Ecosystems

生境 Habitats

生态位 Niche

居群 Populations
遗传多样性 Genetic diversity

居群 Populations

个体 Individuals

染色体 Chromosomes

基因 Genes

核苷酸 Nucleotides

\section{有机体多样性 Organismal diversity}

界 Kingdoms

门 Phyla

科 Families

属 Genera

种 Species

亚种 Subspecies

居群 Populations

文化多样性 Cultural diversity：人类与以上各层次的关系 Human interactions at all levels

图1 生物多样性的组分与层次(修改自Heywood, 1995)

Fig. 1 Compositions and levels of biodiversity (adapted from Heywood, 1995)

种。尽管模式概念受到抨击而被逐步抛弃，但有趣 的是模式标本的方法在大部分情况下还是有效的。 唯一的解释是个体在相当程度上能代表物种但不 能完全代表物种。

此外, 分类学家的工作是鉴定个体和处理各个 类群的关系，但好的分类工作必须坚持居群的概念 与方法(Stebbins, 1963)。我们在1986年就指出：居群 概念和居群研究方法能让人们更准确理解和处理 好物种内的个体变异和变异幅度, 正确处理与物种 鉴定特征(检索表性状)有显著差异的异常个体，较 好理解腊叶标本上的变异以及处理好疑难复合群 (陈家宽和王徽勤, 1986)。洪先生在文中详述的药药 属植物的 5 个案例, 也充分说明了居群概念与方法 的重要性。

第三，居群、物种与生物多样性。生物学界公 认的生物学谱是基因、细胞、器官、个体、种群和 群落等 6 个层次, 每个层次有每个层次的特征以及 与环境的相互关系, 但对每个层次的认识有助于对 其他层次的认识。现代生物学的分支学科都是以研 究这些层次的特征为基础的。我注意到物种并不在 这一生物学谱之列, 原因是物种只是分类学的基本 单元, 生物学家研究各个物种不同层次上的生物学 问题, 只有在分类学与进化生物学中才与物种直接 打交道。

Heywood在 20 世纪后期对生物多样性的 4 个组 分与层次用图 1 表示, 把生物多样性分为生态多样
性、有机体多样性、遗传多样性和文化多样性, 每 个组分又划分多个层次。引人注意的是: 生态多样 性、有机体多样性和遗传多样性之间共有的层次是 居群。我认为这样安排绝不是随意的, 而是其认为 居群起到连接 3 个组分的重要作用。可惜图1的含义 并没有引起国内生物多样性保护研究者的足够重 视。实际上，我们将生物多样性简单分为生态系统 多样性、物种多样性和遗传多样性 3 个层次并不 全面。

洪德元先生是一位有国际视野的分类与系统 植物学家、进化生物学家和保护生物学家，同时也 是我国这些领域的战略科学家和组织家。在中国实 施创新驱动战略的关键时刻, 他再次引领我们关注 和参与现代生命科学的少数几个核心概念之一 一物种概念的讨论, 无疑是有远见卓识的。我特 撰写此文以表示积极响应。

\section{参考文献}

Chen JK, Wang HQ (1986) The application of the concept and method of population to plant taxonomy. Journal of Wuhan Botanical Research, 4, 377-383. (in Chinese with English abstract) [陈家宽, 王徽勤 (1986) 居群(population)概念和 方法在植物分类学中的应用. 武汉植物学研究, 4, 377-383.]

Fu LK, Jin JM (1992) China Plant Red Data Book, Vol. 1: Rare and Endangered Plants. Science Press, Beijing. (in Chinese) [傅立国, 金鉴明 (1992) 中国植物红皮书: 稀有濒危植 物(第一册). 科学出版社, 北京.]

Heywood VH (translated by Ke ZF) (1979) Plant Taxonomy. 
Edward Arnold, London. (in Chinese) [柯植芬译 (1979) 植物分类学. 科学出版社, 北京.]

Heywood VH (1995) Global Biodiversity Assessment. Cambridge University Press, Cambridge.

Hong DY (2016) Biodiversity pursuits need a scientific and operative species concept. Biodiversity Science, 24, 979999. (in Chinese with English abstract) [洪德元 (2016) 生 物多样性事业需要科学、可操作的物种概念. 生物多样 性, 24, 979-999.]

Mayden RL (2002) On biological species, species concepts and individuation in the natural world. Fish and Fisheries, 3, 171-196.

Stebbins GL (translated by Institute of Genetics, Fudan Uni- versity) (1963) Variation and Evolution in Plants. Columbia University Press, New York. (in Chinese) [复旦大学遗传学 研究所译 (1963) 植物的变异与进化. 科学技术出版社, 上海.]

Wilkins JS (2009) Species: A History of the Idea. University of California Press, Berkeley.

Zhou CF, Yang G (2011) Existence and Definition of Species. Science Press, Beijing. (in Chinese) [周长发, 杨光 (2011) 物种的存在与定义. 科学出版社, 北京.]

(责任编辑：黄祥忠) 